\title{
The Effect of Insulin Resistance and Obesity on Low-Density Lipoprotein Particle Size in Children
}

\author{
Mehmet Emre Taşçılar1, Tolga Özgen², Murat Cihan³, Ayhan Abacıํ, \\ Ediz Yeşilkaya ${ }^{1}$, Ibrahim Eker ${ }^{1}$, Muhiddin Serdar ${ }^{3}$ \\ ${ }^{1}$ Gulhane Military Medical Academy, Department of Pediatrics, Division of Pediatric Endocrinology, Ankara, Turkey \\ ${ }^{2}$ Bakırköy Maternity and Children Diseases Training and Research Hospital, Istanbul, Turkey \\ ${ }^{3}$ Gulhane Military Medical Academy, Department of Biochemistry, Ankara, Turkey
}

\section{ABSTRACT}

Objective: In adults, it was shown that obesity and insulin resistance affect low-density lipoprotein (LDL) particle size and small dense (sd) LDL is associated with cardiovascular diseases. In this study, we investigated the effect of obesity and insulin resistance on LDL particle size.

Methods: Twenty-six obese children (13 girls, 13 boys) with a median age of 10.5 years and 27 healthy control subjects ( 17 girls, 10 boys) with a median age of 11.5 were enrolled in the study.

Results: The number of patients with insulin resistance in the obese group was 15 out of 26 . In the control group, there was no subject with insulin resistance. Serum triglyceride and very LDL (VLDL) levels were higher and serum high-density lipoprotein levels (HDL) were lower in the obese patients than in the controls. There was no statistical difference in the LDL particle size between the two groups (medians: 26.6 vs. 26.7 $\mathrm{nm}(\mathrm{p}=0.575))$. The size of LDL particle was not correlated with body mass index (BMI) standard deviation score (SDS), homeostasis model assessment of insulin resistance (HOMA-IR), or serum lipids.

Conclusion: Measurement of LDL particle size as a routine procedure is not necessary in childhood obesity.

Key words: Low-density lipoprotein particle size, obesity, insulin resistance

Received: 19.12 .2009

Accepted: 25.02.2010

\section{Introduction}

Low-density lipoprotein (LDL) size is heterogeneous in humans and different subtypes of LDL are defined. Among LDL subclasses, two different fractions have been isolated, namely, larger (pattern A) and smaller, more dense particles (pattern B) $(1,2)$. Genetic and environmental factors may affect LDL particle size (1-6). The prevalence of pattern B phenotype is $5-10 \%$ in women and men younger than 20 years and $30 \%$ in older men $(1,2)$. Generally, expression of the small dense LDL (sd-LDL) phenotype appears in adulthood as a result of genetic, as well as environmental factors. Obesity, dyslipidemia and insulin resistance are accepted as important environmental factors leading to the development of pattern B (6,7,9-11).

Frequency of obesity and obesity-related diseases has increased both in adults and children. Obese individuals carry risks of cardiovascular diseases (CVD) (12). Some risk factors may be present at a young age, and in these patients the lifelong approach for prevention of CVD must be initiated $(13,14)$. In recent years, it has been shown that small LDL particle size is associated with atherosclerotic coronary artery disease $(15,16)$. LDL particle size measurement is proposed in adult patients who have a high risk of coronary artery disease (8).

In this study, we aimed to investigate the effects of insulin resistance and obesity on LDL particle size in children and to assess the need for routine measurement of LDL particle size in obese children for the prediction of CVD.

\section{Address for Correspondence}

Tolga Özgen, Bakırköy Maternity and Children Diseases Training and Research Hospital, Yenimahalle, Bakırköy, Istanbul, Turkey

Phone: +90 5325732090 Fax: +90 2126318446 E-mail: drtolgaozgen@yahoo.com

() Journal of Clinical Research in Pediatric Endocrinology, Published by Galenos Publishing. 


\section{Methods}

Twenty-six obese children (13 girls, 13 boys) with a median age of 10.5 and 27 healthy control subjects (17 girls, 10 boys) with a median age of 11.5 were enrolled in the study.

Body mass index (BMI) was calculated as weight in kilograms divided by height in square meters. Subjects who had a BMl above the 95th percentile for age and sex or a BMI standard deviation score (SDS) above +2.0 SD were classified as obese (17). Homeostasis model assessment of insulin resistance (HOMA-IR) index (fasting insulin $x$ fasting glucose/22.5) was used for determining insulin resistance (18). Insulin resistance criteria were HOMA-IR>2.5 for prepubertal children and HOMA-IR>4.0 for adolescents (19).

Children with obesity due to syndromes or other known causes were not taken into the study. Control subjects were healthy children. Sixteen patients in the obese group and 15 children in the control group were pubertal.

All blood samples were taken in the morning between 08.00 and 09.00 hours after an over-night fast. The levels of serum insulin, glucose, total cholesterol, triglyceride, high-density lipoprotein (HDL), very low-density lipoprotein (VLDL) and LDL were measured and the serum samples were stored at $-80^{\circ} \mathrm{C}$ for measuring LDL particle size.

We used polyacrylamide gradient gel electrophoresis to eliminate the interference of fatty acids and devised a simple, precise method of polyacrylamide gradient gel electrophoresis to measure the diameter of $\mathrm{sd}-\mathrm{LDL}$ in serum. We used apoferritin and thyroglobulin, which have a molecular diameter of $12.2 \mathrm{~nm}$ and $17.0 \mathrm{~nm}$, respectively, and standard LDL particles having a diameter of 25.7 and $27.0 \mathrm{~nm}$ as calibrators, estimated by measurement of negative staining of electron microscopy. We also included apoferritin as an internal standard for polyacrylamide gradient gel electrophoresis. The only stain used was Coomassie brilliant blue, and it was used for lipoprotein staining. When we used LDL of $25.73 \mathrm{~nm}$ in diameter as a quality control specimen, the coefficient of variation of the size measurements obtained by our method was less than $1.2 \%$.

Informed parent consent was taken for each child and this study was approved by the local ethics committee.

\section{Statistics}

All statistics were performed using the program SPSS 15.0 for Windows. Mann-Whitney $U$ test was used for comparisons of two groups. Spearman's correlations were used for calculating correlations between parameters.

\section{Results}

The number of patients with insulin resistance in the obese group was 15 out of 26 . In the control group, there was no subject with insulin resistance. The value of HOMA-IR was higher in obese patients than in the controls $(p<0.001)$. Serum triglyceride and VLDL levels were higher and serum HDL level was lower in obese patients than in controls $(p<0.05)$. There was no statistical difference in the LDL particle size between the two groups. Clinical and laboratory features of the groups are shown in Table 1.

Serum triglycerides and VLDL were positively, and HDL was negatively correlated with HOMA-IR (Table 2), while LDL particle size was not correlated with any of these values. The size of LDL particles was not correlated with BMI SDS or HOMA-IR. Four subjects, two in obese group and two in the control group, had sd-LDL.

Table 1. Clinical and laboratory features of the groups (median values and ranges)

\begin{tabular}{lccc}
\hline & Obese (n=26) group & Control (n=27) group & p \\
\hline Age (years) & $10.5(5.4-15.3)$ & $11.5(5-15.3)$ & 0.796 \\
Sex (girls/boys) (ratio) & $13 / 13$ & $17 / 10$ & 0.250 \\
BMI SDS & $2.3(2.1-2.4)$ & $0.1(-1.1-1.6)$ & $<0.001$ \\
HOMA-IR & $3.3(0.9-8.3)$ & $1.8(0.5-3.1)$ & $<0.001$ \\
$\quad$ Prepubertal & $2.2(0.9-7.8)$ & $1.7(0.5-2.2)$ & $<0.001$ \\
$\quad$ Pubertal & $3.9(1.3-8.3)$ & $1.9(0.4-2.3)$ & $<0.001$ \\
HDL (mg/dl) & $46(30-76)$ & $55(24-82)$ & 0.004 \\
LDL (mg/dl) & $106(61-210)$ & $93(53-147)$ & 0.051 \\
VLDL (mg/dl) & $21(6-110)$ & $16(9-41)$ & 0.030 \\
Total cholesterol (mg/dl) & $179(134-295)$ & $163(132-216)$ & 0.206 \\
Triglycerides (mg/dl) & $107(32-444)$ & $82(44-237)$ & 0.031 \\
LDL particle size (nm) & $26.6(25.3-27.6)$ & $26.7(25.1-28.1)$ & 0.575 \\
\hline BMI SDS: body mass index standard deviation score; HOMA-IR: Homeostatic assessment of insulin resistance; HDL: high density lipoprotein; LDL: low density lipoprotein; \\
VLDL: very low density lipoprotein & &
\end{tabular}


Taşcılar ME et al.

LDL Particle Size in Obese Children

Table 2. Correlation coefficients between HOMA-IR, LDL particle size and serum lipids

\begin{tabular}{lcccccc}
\hline & & Total cholesterol & Triglycerides & HDL & VLDL & LDL \\
\hline HOMA-IR & $\mathrm{r}$ & 0.173 & 0.513 & -0.281 & 0.516 & 0.136 \\
& $\mathrm{p}$ & 0.217 & $<0.001$ & 0.041 & $<0.001$ & 0.330 \\
LDL particle size & $\mathrm{r}$ & -0.152 & 0.030 & -0.185 & 0.027 & -0.167 \\
& $\mathrm{p}$ & 0.277 & 0.831 & 0.184 & 0.846 & 0.261 \\
\hline
\end{tabular}

HOMA-IR: Homeostatic assessment of insulin resistance; HDL: high density lipoprotein; LDL: low density lipoprotein; VLDL: very low density lipoprotein; $r=$ correlation coefficient; $p=$ significance

\section{Discussion}

In this study, we investigated LDL particle size in obese children and its relationship with insulin resistance and serum lipid levels. Obesity, the expanding problem of the world, precipitates cardiovascular diseases. Autopsy studies have demonstrated that atherosclerotic process begins in childhood $(20,21)$. Some risk factors for ischemic heart diseases in the obese population are dyslipidemia, hypertension and insulin resistance (22). In recent years, small LDL particle size has been suggested to be one of the risk factors. Different mechanisms have been proposed for atherogenicity of sd-LDL $(23,24)$. Björnheden at al (24) have reported that $\mathrm{sd}-\mathrm{LDL}$ may be taken up easily by arterial tissue because of greater transendothelial transport of smaller particles (24).

It has been reported that the prevalence of sd-LDL was $9.3 \%$ in children (25) and $44 \%$ in adults (26). Miyashita et al (27) reported that $40 \%$ of obese children have sd-LDL. In our study, the prevalence of sd-LDL in the obese group was not as high as that reported by Miyashita's group. Different factors may play a role in the explanation of our results. Firstly, the genetic make-up of the Turkish population may be different. Genetic factors are important. Previously, the inheritance of sd-LDL was reported as autosomal dominant (28). It has been reported that dominant inheritance has an age-dependent penetration. Our group of subjects was also younger than Miyashita's group. Shea et al (29) have demonstrated that plasma insulin may modulate lipid levels and particle size in very young children. Rainwanter et al (30) have reported that young men and women had a lower prevalence of small LDL than men and women of an older age.

In adults, it has been demonstrated that serum triglyceride levels are major determinants of LDL particle size (31). In case of hypertriglyceridemia, VLDL transfers its triglycerides to HDL. Triglycerides of this HDL are transferred to the LDL and the cholesterol of LDL is removed from the molecule. This form of LDL with high triglyceride and low cholesterol becomes smaller and denser $(32,33)$. Obesity is another factor that influences LDL particle size (34). Yoshino et al (35) have reported that LDL particle size increases with weight reduction, although serum lipids do not change significantly.
In our study group, we did not find any relationship between obesity and LDL particle size. Dyslipidemia existed in our children, nevertheless, it did not have any correlation with the pathological clinical and laboratory findings. Although obese children had higher triglycerides and lower HDL than controls, LDL particle size did not have any correlation with these laboratory findings and obesity.

In conclusion, according to our results, it is not necessary to evaluate routinely LDL particle size in obese children. Additional studies with a large number of subjects are needed to evaluate more definitely LDL particle size status, especially in children.

\section{References}

1. Packard CJ, Shepherd J. Lipoprotein heterogeneity and apolipoprotein B metabolism. Arterioscler Thromb Vasc Biol 1997;17:3542-3456. [Abstract] / [Full Text]

2. Rizzo M, Berneis $K$. The clinical significance of the size of low-density-lipoproteins and the modulation of subclasses by fibrates. Curr Med Res Opin 2007;23:1103-1111. [Abstract] / [PDF]

3. Vora AN, Ouyang P, Bittner V Tardif JC, Waters DD, Vaidya D. Racial differences of lipoprotein subclass distributions in postmenopausal women. Ethn Dis 2008;18:176-180. [Abstract] / [Full Text]

4. Bossé Y, Feitosa MF, Després JP, Lamarche B, Rice T, Rao DC, Bouchard C, Pérusse L, Vohl MC. Detection of a major gene effect for LDL peak particle diameter and association with apolipoprotein H gene haplotype. Atherosclerosis 2005;182:231-239. [Abstractl/ [Full Text]

5. Austin MA. Genetic epidemiology of low-density lipoprotein subclass phenotypes. Ann Med 1992;24:477-481. [Abstract] / [PDF]

6. Bioletto S, Golay A, Munger R, Kalix B, James RW. Acute hyperinsulinemia and very-low-density and low-density lipoprotein subfractions in obese subjects. Am J Clin Nutr 2000;71:443-449. [Abstract] / [Full Text] / [PDF]

7. Berneis K, Rizzo M. LDL size: does it matter? Swiss Med Wkly 2004;134:720-724. [Abstract] / [PDF]

8. Rizzo M, Berneis K. Should we measure routinely the LDL peak particle size? Int J Cardiol 2006;107:166-170. [Abstract] / [Full Text] / [PDF]

9. King RF, Hobkirk JP, Cooke CB, Radley D, Gately PJ. Low-density lipoprotein sub-fraction profiles in obese children before and after attending a residential weight loss intervention. J Atheroscler Thromb 2008;15:100-107. [Abstract] / [PDF]

10. Magkos F, Mohammed BS, Mittendorfer B. Effect of obesity on the plasma lipoprotein subclass profile in normoglycemic and normolipidemic men and women. Int $\mathrm{J}$ Obes (Lond) 2008;32:1655-1664. [Abstract] / [Full Text] / [PDF] 
11. Rivellese AA, Patti L, Kaufman D, Zhu J, Annuzzi G, Vaccaro O, Ebbesson SO, Howard WJ, Riccardi G, Howard BV. Lipoprotein particle distribution and size, insulin resistance, and metabolic syndrome in Alaska Eskimos: The GOCADAN study. Atherosclerosis 2008;200:350-358. [Abstract] / [Full Text] / [PDF]

12. Bahrami H, Bluemke DA, Kronmal R, Bertoni AG, Lloyd-Jones DM, Shahar E, Szklo M, Lima JA. Novel metabolic risk factors for incident heart failure and their relationship with obesity: the MESA (Multi-Ethnic Study of Atherosclerosis) study. J Am Coll Cardiol 2008;51:1775-1783. [Abstract] / [Full Text] / [PDF]

13. Daniels SR, Greer FR; Committee on Nutrition. Lipid screening and cardiovascular health in childhood. Pediatrics 2008;122:198-208. [Abstract] / [PDF]

14. Webber LS, Osganian V, Luepker RV, Feldman HA, Stone EJ, Elder JP, Perry CL, Nader PR, Parcel GS, Broyles SL, McKinlay SM, CATCH Study Group. Cardiovascular risk factors among third grade children in four regions of the United States. The CATCH Study: Child and Adolescent Trial for Cardiovascular Health. Am J Epidemiol 1995;141:428-439. [Abstract] / [PDF]

15. Mykkänen L, Kuusisto J, Haffner SM, Laakso M, Austin MA LDL size and risk of coronary heart disease in elderly men and women. Arterioscler Thromb Vasc Biol 1999;19:2742-2748. [Abstract] / [Full Text] / [PDF]

16. Lamarche B, St-Pierre AC, Ruel IL Cantin B, Dagenais GR, Després JP. A prospective, population-based study of low density lipoprotein particle size as a risk factor for ischemic heart disease in men. Can J Cardiol 2001;17:859-865. [Abstract] / [PDF]

17. Kuczmarski RJ, Ogden CL, Grummer-Strawn LM, Flegal KM, Guo SS, Wei R, Mei Z, Curtin LR, Roche AF, Johnson CL. CDC growth charts: United States. Adv Data 2000;314:1-27. [Abstract] / [PDF]

18. Matthews DR, Hosker JP, Rudenski AS Naylor BA, Treacher DF, Turner RC. Homeostasis model assessment: insulin resistance and b-cell function from fasting plasma glucose and insulin concentrations in man. Diabetologia 1985;28:412-419. [Abstract] / [PDF]

19. Valerio G, Licenziati MR, lannuzzi A, Franzese A, Siani $P$, Riccardi G, Rubba P. Insulin resistance and impaired glucose tolerance in obese children and adolescents from Southern Italy. Nutr Metab Cardiovasc Dis 2006;16:279-284. [Abstract] / [Full Text] / [PDF]

20. Newman WP, Freedman DS, Voors AW, Gard PD, Srinivasan SR, Cresanta JL, Williamson GD, Webber LS, Berenson GS. Relation of serum lipoprotein levels and systolic blood pressure to early atherosclerosis: the Bogalusa Heart Study. N Engl J Med 1986;314:138-144. [Abstract]

21. Berenson GS, Srinivasan SR, Bao W, Newman WP, Tracy RE, Wattigney WA. Association between multiple cardiovascular risk factors and the early development of atherosclerosis. Bogalusa Heart Study. N Engl J Med 1998;338:1650-1656. [Abstract] / [PDF]
22. Ross R. The pathogenesis of atherosclerosis: an update. N Engl J Med 1986;314:488-500. [Abstract]

23. Galeano NF, Al-Haideri M, Keyserman F, Rumsey SC, Deckelbaum RJ. Small dense low density lipoprotein has increased affinity for LDL receptor-independent cell surface binding sites: a potential mechanism for increased atherogenicity. J Lipid Res 1998;39:1263-1273. [Abstract] / [PDF]

24. Björnheden T, Babyi A, Bondjers G, Wiklund O. Accumulation of lipoprotein fractions and subfractions in the arterial wall, determined in an in vitro perfusion system. Atherosclerosis 1996;123:43-56. [Abstract] / [PDF]

25. Arisaka O, Fujiwara S, Yabuta K, Mokuno H, Mitugi Y, Miyake $\mathrm{N}$. Characterization of low-density lipoprotein subclasses in children. Metabolism 1997;46:146-148. [Abstract] / [PDF]

26. Austin MA, King MC, Vranizan KM, Krauss RM. A proposed genetic marker for coronary heart disease risk. Circulation 1990;82:495-506. [Abstract] / [PDF]

27. Miyashita M, Okada T, Kuromori Y, Harada K. LDL particle size, fat distribution and insulin resistance in obese children. Eur J Clin Nutr 2006;60:416-420. [Abstract] / [PDF]

28. Austin MA, King MC, Vranizan KM, Newman B, Krauss RM. Inheritance of low-density lipoprotein subclass patterns: results of complex segregation analysis. Am J Hum Genet 1988;43:838-846. [Abstract] / [PDF]

29. Shea S, Aymong $E$, Zybert $P$, Berglund $L$, Shamoon $H$, Deckelbaum RJ, Basch CE. Fasting plasma insulin modulates lipid levels and particle sizes in 2- to 3-year-old children. Obes Res 2003;11:709-721. [Abstract] / [Full Text]

30. Rainwater DL, Almasy L, Blangero J, Cole SA, VandeBerg JL, MacCluer JW, Hixson JE. A genome search identifies major quantitative trait loci on human chromosomes 3 and 4 that influence cholesterol concentrations in small LDL particles. Arterioscler Thromb Vasc Biol 1999;19:777-783. [Abstract] / [PDF]

31. Gazi IF, Filippatos TD, Tsimihodimos V, Saougos VG, Liberopoulos EN, Mikhailidis DP, Tselepis AD, Elisaf M. The hypertriglyceridemic waist phenotype is a predictor of elevated levels of small, dense LDL cholesterol. Lipids 2006;41:647-654. [Abstract]

32. Lemieux I, Pascot A, Couillard C Lamarche B, Tchernof A, Alméras N, Bergeron J, Gaudet D, Tremblay G, Prud'homme D, Nadeau A, Després JP. Hypertriglyceridemic waist: A marker of the atherogenic metabolic triad (hyperinsulinemia; hyperapolipoprotein B; small, dense LDL) in men? Circulation 2000;102:179-184. [Abstract] / [Full Text] / [PDF]

33. Hirano T, Yoshino G, Kazumi T. Troglitazone and small low-density lipoprotein in type 2 diabetes. Ann Intern Med 1998;129:162-163. [Abstract] / [Full Text] / [PDF]

34. Barakat HA, McLendon VD, Marks R, Pories W, Heath J, Carpenter JW. Influence of morbid obesity and non-insulindependent diabetes mellitus on high-density lipoprotein composition and subpopulation distribution. Metabolism 1992;41:37-41. [Abstract] / [PDF]

35. Yoshino G, Hirano T, Kazumi T. Treatment of small dense LDL. J Atheroscler Thromb 2002;9:266-275. [Abstract] / [PDF] 